\title{
Pelaksanaan Inspeksi Keselamatan pada Perlintasan Sebidang JPL 349 KM 163+758, Jalan Timoho, Yogyakarta
}

\author{
(Safety Inspection Application on Level Crossing JPL 349 KM 163+758, Timoho Street, Yogyakarta)
}

\author{
NOOR MAHMUDAH, DIAN M SETIAWAN, RISTACYA DEVI RAMANTI
}

\begin{abstract}
ABSTRAK
Kecelakaan yang terjadi antara kendaraan jalan raya dan kereta api dapat terjadi di perlintasan sebidang walaupun sudah dilengkapi dengan prasarana yang telah ditentukan. Penelitian ini bertujuan untuk menginspeksi keselamatan perlintasan sebidang di JPL 349, Jalan Timoho, Yogyakarta, karena lokasi perlintaasan sebidang ini berdekatan dengan pusat kegiatan masyarakat. Metode penelitian ini diawali dengan studi pustaka dan pengumpulan data primer dan data sekunder. Data primer terdiri dari data kelengkapan infrastruktur, data geometrik, volume lalulintas, tundaan lalulintas, panjang antrian kendaraan, dan indeks kondisi struktur perkerasan (Pavement Condition Index). Sementara itu, data sekunder berupa jadwal kedatangan dan keberangkatan kereta api. Hasil penelitian ini menunjukkan bahwa perlintasan sebidang JPL 349 tidak memenuhi persyaratan yang berlaku terkait dengan rambu, marka, interval waktu kedatangan kereta api, sudut perpotongan perlintasan, jarak antara perlintasan sebidang yang berdekatan, dan alinemen horizontal. Tundaan lalulintas terlama ialah sebesar 194 detik dan antrian kendaraan terpanjang ialah 210 meter. Selain itu, disimpulkan bahwa nilai indeks kondisi struktur perkerasan ialah sebesar $72.9 \%$ (sangat bagus).
\end{abstract}

Kata kunci: perlintasan sebidang, kereta api, inspeksi keamanan, tundaan lalulintas, panjang antrian kendaraan

\section{ABSTRACT}

Accidents between motorized vehicles and trains may occur at level crossings even though it has been maintained and given an adequate infrastructure. This study aims to conduct a safety inspections at JPL 349, Timoho Street, Yogyakarta since the level crossing location close to the center of human activity. This research method begins with a literature study and primary and secondary data collection. The primary data consisted of infrastructure completeness data, highway and rail track geometric, traffic volume, traffic delay, vehicles queue length, and pavement condition index (PCI). While secondary data was in the form of train departure and arrival schedules. The conclusions of this study stated that the JPL 349 level crossing do not meet the applicable regulatory standards in terms of signs, markers, train travel time intervals, intersection angles between highway and rail track, and the distance between level crossings. In terms of geometric, the horizontal alignment of the highway was also not in accordance with the applicable regulations. The longest traffic delay was 194 seconds and the longest queue of vehicles was $210 \mathrm{~m}$. In addition, it was known that the average PCI was $72.9 \%$ (very good).

Keywords: level crossing, railways, safety inspection, delay, vehicle queue length

\section{PENDAHULUAN}

Pertumbuhan penduduk menjadi parameter penting dalam perkembangan suatu wilayah, yang menjadi pemicu timbulnya permasalahan arus lalu lintas pada sistem transportasi, terutama pada pertemuan dua ruas jalan raya dengan jalur kereta api. Wilayah Provinsi Yogyakarta masuk dalam pengawasan DAOP 
(Daerah Operasi) VI PT. Kereta Api Indonesia, yang memiliki sekitar 499 perlintasan sebidang. Berdasarkan jumlah tersebut, perlintasan sebidang yang dijaga oleh PT. KAI hanya sejumlah 122 perlintasan dan sebanyak 309 perlintasan lainnya tidak dijaga, serta 68 perlintasan memiliki status perlintasan sebidang tidak resmi.

Selain itu diperkirakan beberapa perlintasan sebidang tersebut memiliki potensi terjadinya kecelakaan, salah satunya pada perlintasan sebidang JPL 349 KM 163+758, yang berpotongan dengan Jalan Timoho, Yogyakarta. Perlintasan sebidang tersebut terletak di Kecamatan Gondokosuman, Kota Yogyakarta yang dijaga resmi oleh PT. KAI bagian Departemen Jalan dan Jembatan. Perlintasan tersebut diketahui berdekatan dengan berbagai macam pusat aktivitas manusia, seperti kantor pemerintahan, sekolah, universitas, dan sebagainya. Oleh karena itu penulis berpendapat perlu dilakukan Inspeksi Keselamatan Perlintasan Sebidang pada lokasi tersebut.

Maksud dari penelitian ini adalah untuk melakukan inspeksi keselamatan pada perlintasan sebidang JPL 349 KM 163+758, Jalan Timoho, Yogyakarta yang diharapkan dapat meningkatkan keselamatan para pengguna jalan raya dan jalan rel pada perlintasan sebidang. Penelitian ini bertujuan untuk mengevaluasi spesifikasi teknis perlintasan sebidang yang berupa kelengkapan infrastruktur dan geometrik, menganalisis volume lalu lintas, panjang antrian dan tundaan kendaraan di jalan raya, serta menganalisis keadaan struktur perkerasan jalan menggunakan metode Pavement Condition Index (PCI).

Di dalam Undang-undang Republik Indonesia Nomor 22 Tahun 2009 tentang Lalu Lintas dan Angkutan Jalan, terdapat pernyataan bahwa yang dimaksud dengan keselamatan lalu lintas dan angkutan jalan adalah suatu keadaan terhindarnya setiap orang dari resiko kecelakaan selama berlalu lintas yang disebabkan oleh manusia, kendaraan, jalan, dan/atau lingkungan. Yulisetianto (2008) dalam Pramono (2016) menyatakan bahwa fungsi keselamatan adalah untuk menerapkan tempat dan menentukan kesalahan operasional yang mendorong terjadinya kecelakaan. Fungsi ini pada umumnya dilakukan dengan menganalisis penyebab kecelakaan terjadi, kemudian mengevaluasi langkah-langkah pencegahan yang telah dilakukan. Fungsi keselamatan bukanlah reaksi ataupun tindakan untuk mengatasi kecelakaan yang terjadi dan juga bukan untuk mencari kesalahan orang tetapi untuk meneliti dan mengevaluasi bagian manajemen tertentu yang memungkinkan terjadinya suatu kecelakaan.

Menurut Hasan (2009), terdapat beberapa faktor yang mempengaruhi keselamatan pada perlintasan sebidang, diantaranya adalah:

1. Kondisi kendaraan maupun pengemudi.

2. Kondisi alam (cuaca).

3. Desain ruas perpotongan jalur kereta api dengan jalan (alinyemen vertikal dan horisontal).

4. Kondisi kerusakan struktur perkerasan jalan.

5. Kelengkapan rambu dan marka.

Inspeksi keselamatan pada perlintasan sebidang adalah kegiatan pemeriksaan atau observasi secara detail pada perlintasan sebidang untuk mendapatkan verifikasi bahwa kondisi perlintasan pada lokasi tersebut telah memenuhi standar peraturan yang berlaku.

Sesuai Undang-undang No. 23 Tentang Perkeretaapian Tahun 2007 bahwa Penjaga Pintu dan Lintasan bertugas menyelamatkan perjalanan kereta api dari sisi perlintasan. Seperti yang telah ditetapkan di dalam Peraturan Menteri Perhubungan Nomor 36 Tahun 2011 Tentang Perpotongan dan Persinggungan antara Jalur Kereta Api dengan Bangun Lain, persyaratan perlintasan sebidang adalah sebagai berikut:

1. Jarak waktu antar kereta api yang menuju perlintasan (searah maupun berlawanan arah tujuan) minimal 30 menit.

2. Jalan yang berpotongan dengan jalan kereta api adalah maksimal jalan kelas III.

3. Jarak antara perlintasan yang satu dengan perlintasan berikutnya minimal 800 meter.

4. Perlintasan sebidang tidak berlokasi pada lengkungan jalur kereta api ataupun jalan raya.

5. Tepat pada perkerasan jalan raya di titik potongan dengan rel kereta api memiliki permukaan datar sepanjang $60 \mathrm{~cm}$ diukur dari sisi terluar rel kereta api.

6. Lebar perlintasan sebidang dari sisi jalan raya untuk satu jalur memiliki lebar maksimum 7 meter.

7. Sudut yang terbentuk antara perpotongan jalan kereta api dengan jalan raya harus $90^{\circ}$, 
dan panjang lurusan jalan raya disyaratkan minimal 150 meter diukur dari as jalan rel.

Berdasarkan Peraturan Direktorat Jenderal Perhubungan Darat (2005) Nomor: SK.770/KA.401/DRJD/2005 tentang Pedoman Teknis Perlintasan Sebidang antara Jalan Raya dengan Jalan Kereta Api (Gambar 1), dinyatakan bahwa prasarana yang wajib dimiliki oleh jalan raya pada perlintasan sebidang adalah:

1. Rambu untuk fungsi peringatan.

2. Rambu untuk fungsi larangan.

3. Marka jalan.

4. Pita penggaduh.

5. Median pada jalan 2 lajur 2 arah.

6. Isyarat lampu berwarna merah dan isyarat suara.

7. Pintu perlintasan.

\section{METOde PENELITIAN}

Adapun tahapan penelitian ini dimulai dengan studi pustaka dan survai pendahuluan (observasi) agar proses pengumpulan data primer maupun data sekunder dapat dilakukan dengan optimal dan efisien.

Adapun data primer yang digunakan pada penelitian ini ialah:

1. Data mengenai kelengkapan jalan raya di perlintasan sebidang.

2. Data mengenai kelengkapan jalur kereta api di perlintasan sebidang.
3. Data geometrik jalan raya dan jalur kereta api.

4. Volume lalu lintas, tundaan, panjang antrian perlintasan sebidang.

5. Kondisi struktur perkerasan jalan.

Sedangkan data sekunder yang digunakan pada penelitian ini ialah:

1. Jadwal keberangkatan dan kedatangan kereta api.

2. Grafik perjalanan kereta api.

3. Data perlintasan wilayah DAOP VI Yogyakarta.

Data primer dan data sekunder tersebut digunakan untuk:

1. Menganalisis kelengkapan infrastruktur pada perlintasan sebidang sesuai Peraturan Menteri Perhubungan Nomor 36 Tahun 2011 Tentang Perpotongan dan Persinggungan antara Jalur Kereta Api dan Bangunan lain dan Surat Keputusan Direktorat Jenderal Perhubungan Darat Nomor 770 Tahun 2005.

2. Menganalisis karakteristik lalu lintas berupa volume lalu lintas, tundaan, dan panjang antrian kendaraan sesuai Pedoman Kapasitas Jalan Indonesia, 2014.

3. Menganalisis kondisi jalan raya dengan menggunakan metode Indeks Kondisi Perkerasan (PCI).

4. Usulan desain ulang geometrik jalan raya.

Penelitian ini dilakukan di perlintasan sebidang JPL 349 KM 163 + 758, Jalan Timoho, Yogyakarta, seperti yang ditunjukkan oleh Gambar 2.

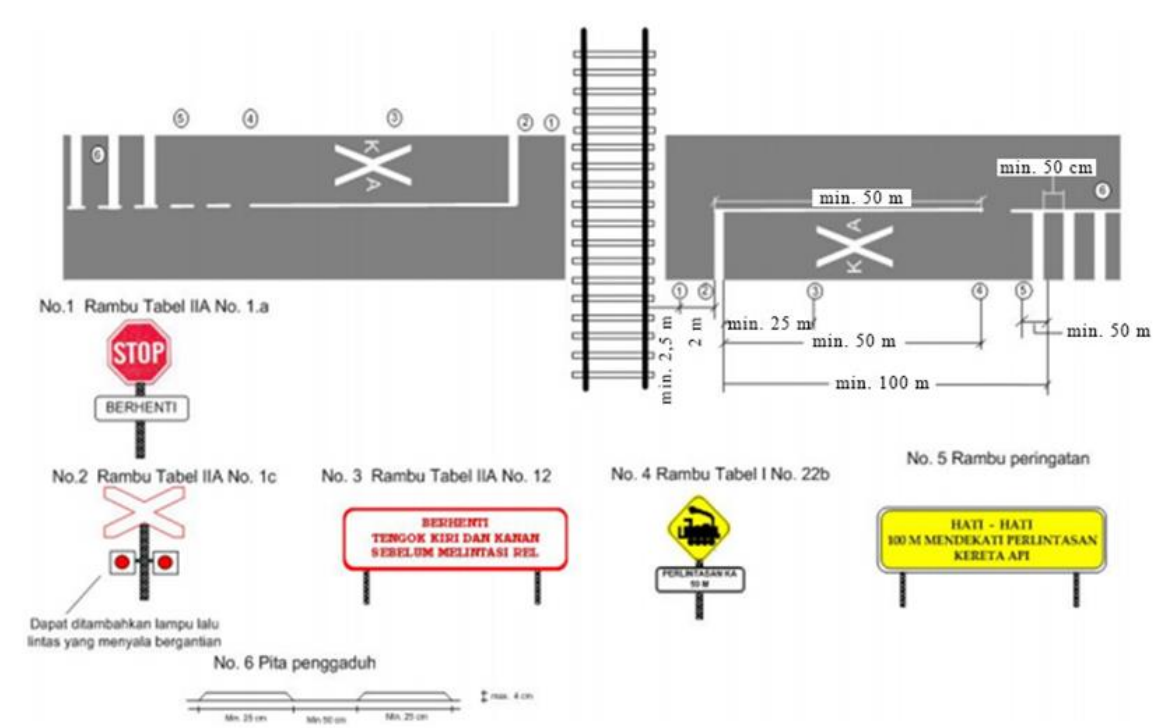

GAMBAR 1. Contoh pemasangan perlengkapan jalan pada perlintasan sebidang (sumber : Direktorat Jenderal Perhubungan Darat, 2005) 
Data primer dan data sekunder tersebut digunakan untuk:

1. Menganalisis kelengkapan infrastruktur pada perlintasan sebidang sesuai Peraturan Menteri Perhubungan Nomor 36 Tahun 2011 Tentang Perpotongan dan Persinggungan antara Jalur Kereta Api dan Bangunan lain dan Surat Keputusan Direktorat Jenderal Perhubungan Darat Nomor 770 Tahun 2005.

2. Menganalisis karakteristik lalu lintas berupa volume lalu lintas, tundaan, dan panjang antrian kendaraan sesuai Pedoman Kapasitas Jalan Indonesia, 2014.

3. Menganalisis kondisi jalan raya dengan menggunakan metode Indeks Kondisi Perkerasan (PCI).

4. Usulan desain ulang geometrik jalan raya.

Penelitian ini dilakukan di perlintasan sebidang JPL 349 KM 163 + 758, Jalan Timoho, Yogyakarta, seperti yang ditunjukkan oleh Gambar 2 berikut.

\section{HASIL DAN PEMBAHASAN}

Analisis telah dilakukan terhadap persyaratan kriteria standard teknis perlintasan sebidang, alinyemen horizontal jalan raya, volume lalu lintas, tundaan dan panjang antrian kendaraan di jalan raya, dan kondisi kerusakan struktur perkerasan jalan.

\section{Persyaratan Teknis Perlintasan Sebidang}

Hasil analisis persyaratan kriteria standar teknis perlintasan sebidang berdasarkan Surat Keputusan Direktorat Jenderal Perhubungan Darat Nomor 770 (2005) disajikan pada Tabel 1 berikut.

\section{Alinyemen Horisontal Jalan Raya}

Berdasarkan hasil perancangan ulang alinyemen horizontal jalan raya yang telah dilakukan, terdapat perbedaan hasil dengan kondisi eksisting trase jalan raya, dimana sudut tikungan dan jari-jari tikungan menjadi lebih besar. Hal ini dimaksudkan agar jarak pandang pengendara saat akan melintasi perlintasan sebidang menjadi lebih baik dari sebelumnya dan tingkat keselamatan pengendara akan meningkat. Namun di sisi lain, dampak negatifnya yang ditimbulkan adalah diperlukan pembebasan lahan untuk merealisasikan hasil perancangan ulang tersebut (Gambar 3).

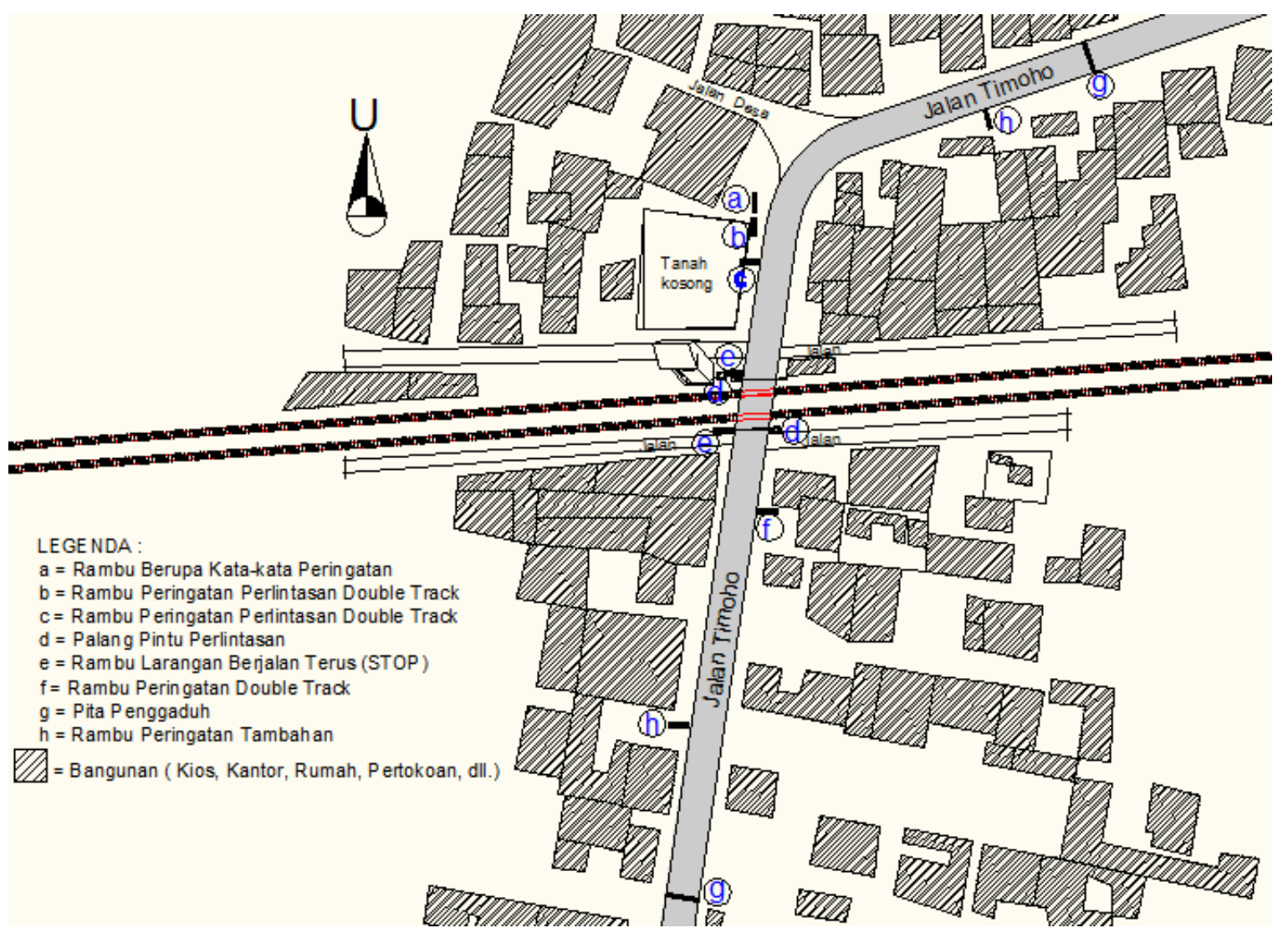

GAMBAR 2. Lokasi penelitian 
TABEL 1. Hasil analisis persyaratan teknis perlintasan sebidang

\begin{tabular}{|c|c|c|c|c|}
\hline No. & $\begin{array}{l}\text { Syarat Teknis SK Direktorat Jenderal } \\
\text { Perhubungan Darat Nomor } 770(2005)\end{array}$ & Memenuhi & $\begin{array}{l}\text { Tidak } \\
\text { Memenuhi }\end{array}$ & Keterangan \\
\hline 1. & $\begin{array}{l}\text { Perbedaan waktu antar kereta api yang melintas } \\
\text { di perlintasan sebidang ialah lebih dari } 30 \text { menit. }\end{array}$ & & $\mathrm{v}$ & $\begin{array}{l}\text { Selang waktu tercepat } \\
\text { adalah } 7 \text { menit. }\end{array}$ \\
\hline 2. & $\begin{array}{l}\text { Jarak antar perlintasan sebidang tidak kurang } \\
800 \text { meter. }\end{array}$ & & $\mathrm{V}$ & $\begin{array}{l}537 \mathrm{~m} \text { ke arah timur } \\
780 \mathrm{~m} \text { ke arah barat. }\end{array}$ \\
\hline 3. & Jalan yang melintas adalah jalan kelas III. & $\mathrm{v}$ & & \\
\hline 4. & $\begin{array}{l}\text { Perlintasan sebidang tidak terletak pada } \\
\text { lengkungan jalur kereta api maupun jalan raya. }\end{array}$ & $\mathrm{V}$ & & \\
\hline 5. & $\begin{array}{l}\text { Tepat pada perkerasan jalan raya di titik } \\
\text { potongan dengan rel kereta api memiliki } \\
\text { permukaan datar sepanjang } 60 \mathrm{~cm} \text { diukur dari } \\
\text { sisi terluar rel kereta api }\end{array}$ & & $\mathrm{v}$ & $\begin{array}{l}\text { Terdapat permukaan } \\
\text { datar sepanjang } 35 \\
\text { cm di sisi selatan dan } \\
47 \mathrm{~cm} \text { di sisi utara. }\end{array}$ \\
\hline 6. & $\begin{array}{l}\text { Lebar perlintasan sebidang dari sisi jalan raya } \\
\text { untuk satu jalur memiliki lebar maksimum } 7 \\
\text { meter. }\end{array}$ & $\mathrm{v}$ & & \\
\hline 7. & $\begin{array}{l}\text { Sudut yang terbentuk antara perpotongan jalan } \\
\text { kereta api dengan jalan raya harus } 90^{\circ} \text {. }\end{array}$ & & $\mathrm{v}$ & $\begin{array}{l}\text { Sudut perpotongan } \\
77^{0} \text {. }\end{array}$ \\
\hline 8. & $\begin{array}{l}\text { Panjang lurusan jalan raya disyaratkan minimal } \\
150 \text { meter diukur dari as jalan rel. }\end{array}$ & & $\mathrm{v}$ & $\begin{array}{l}\text { Di arah timur terdapat } \\
\text { tikungan dengan jarak } \\
38 \text { m dari as } \\
\text { perlintasan sebidang. }\end{array}$ \\
\hline 9. & Rambu peringatan dan larangan. & & $\mathrm{v}$ & $\begin{array}{l}\text { Tidak terdapat rambu } \\
\text { dilarang balik arah. }\end{array}$ \\
\hline 10. & Marka jalan. & & $\mathrm{v}$ & $\begin{array}{l}\text { Tidak ada marka } \\
\text { jalan. }\end{array}$ \\
\hline 11. & Pita penggaduh. & $\mathrm{v}$ & & \\
\hline 12. & Isyarat lampu berwarna merah dan isyarat suara. & $\mathrm{v}$ & & \\
\hline 13. & Palang pintu. & $\mathrm{v}$ & & \\
\hline 14. & $\begin{array}{l}\text { Prasarana fisik dan non fisik di perlintasan yang } \\
\text { berupa pos jaga, petugas penjaga perlintasan } \\
\text { sebidang, genta, daftar semboyan, dan daftar } \\
\text { grafik perjalanan kereta api. }\end{array}$ & $\mathrm{V}$ & & \\
\hline
\end{tabular}

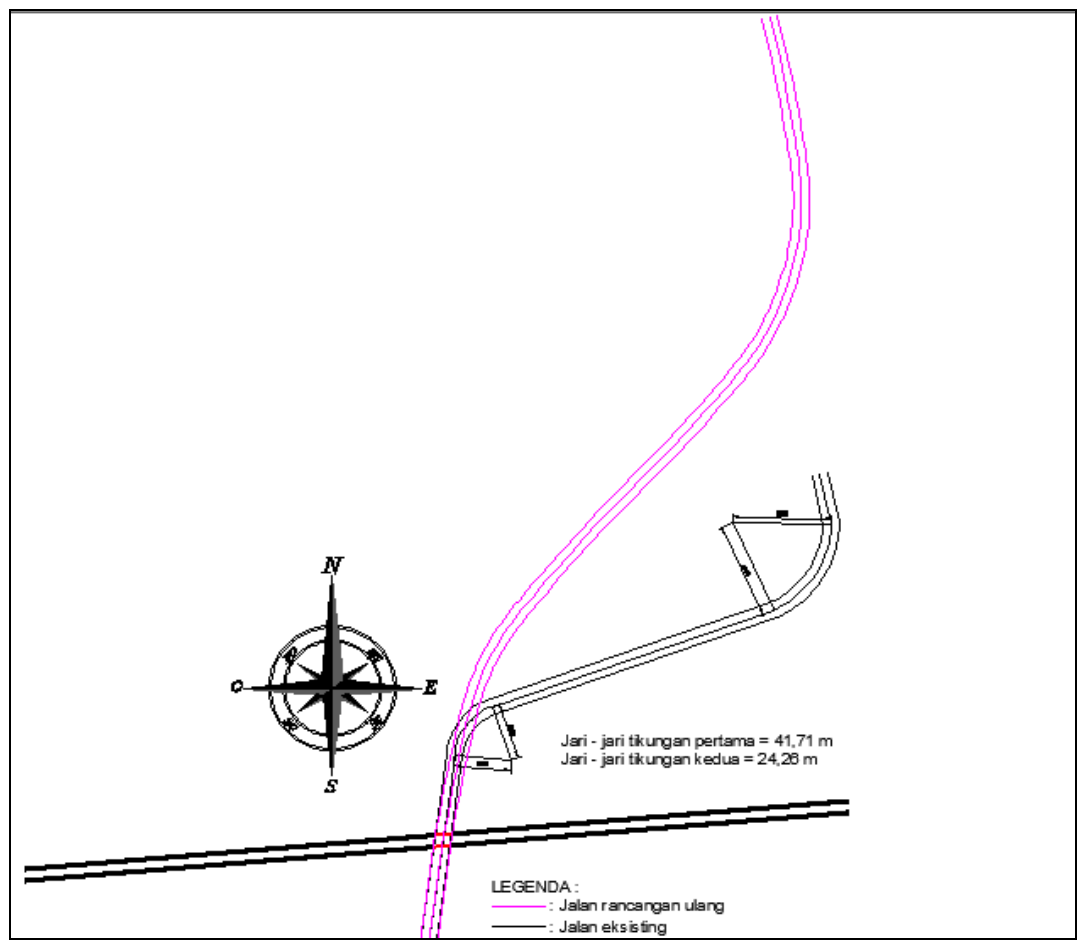

GAMBAR 3. Tikungan eksisting (garis hitam) dan hasil perancangan ulang alinyemen horizontal (garis ungu) 


\section{Analisis Volume Lalu Lintas}

Berdasarkan survai lapangan dan analisis data yang telah dilakukan (Gambar 4), diperoleh nilai arus lalu lintas pada hari libur dengan total sebesar $3.432 \mathrm{kend} /$ jam dari arah Selatan. Kemudian hasil tersebut dikalikan dengan nilai ekivalen kendaraan ringan (ekr) dari masingmasing jenis kendaraan sehingga diperoleh hasil sebesar 1.789,2 skr/jam. Sedangkan dari arah Utara didapatkan total arus lalu lintas sebesar $3.756 \mathrm{kend} / \mathrm{jam}$ atau sebesar 1.862,4 skr/jam.

Selanjutnya pada hari kerja didapatkan hasil total arus lalu lintas sebesar $3.904 \mathrm{kend} / \mathrm{jam}$ atau sebesar $1.888 \mathrm{skr} / \mathrm{jam}$ dari arah Selatan. Sedangkan dari Utara didapatkan total arus lalu lintas sebesar $3.932 \mathrm{kend} / \mathrm{jam}$ atau sebesar $1.922 \mathrm{skr} / \mathrm{jam}$. Sehingga dapat disimpulkan bahwa pada hari libur, arus lalu lintas di Jalan Timoho cenderung lebih kecil dibandingkan dengan arus lalu lintas pada hari kerja, karena Jalan Timoho merupakan kawasan pendidikan dan perkantoran. Selain itu, diketahui bahwa nilai arus lalu lintas yang datang dari arah Utara lebih besar dibandingkan arus lalu lintas yang datang dari arah Selatan baik di hari libur maupun di hari kerja.

\section{Analisis Tundaan dan Panjang Antrian}

Berdasarkan hasil analisis survai pada hari sabtu (akhir pekan) yang tersaji pada Gambar 5, dapat disimpulkan bahwa tundaan terlama terjadi pada pukul 10:19 WIB dengan nilai tundaan selama 194 detik dan durasi proses pergerakan pintu perlintasan dimulai dari pintu perlintasan ditutup hingga pintu perlintasam dibuka membutuhkan waktu selama 210 detik. Tundaan tersebut terjadi karena terdapat 2 kedatangan kereta api yang melintas dari arah Barat dan dari arah Timur. Tundaan tersebut juga menyebabkan panjang antrian pada pintu Selatan sepanjang $150 \mathrm{~m}$ dengan jumlah kendaraan ringan sebanyak 26 kendaraan dan jumlah sepeda motor sebanyak 74 kendaraan (Gambar 6). Sedangkan panjang antrian yang terjadi pada pintu Utara ialah sepanjang $110 \mathrm{~m}$ dengan jumlah kendaraan ringan sebanyak 32 kendaraan dan jumlah sepeda motor sebanyak 110 kendaraan (Gambar 6).

Selanjutnya tundaan tersingkat pada akhir pekan terjadi pada pukul 08:53 dengan tundaan selama 43 detik dan durasi proses pergerakan pintu perlintasan dimulai dari pintu perlintasan ditutup hingga pintu perlintasan dibuka membutuhkan waktu selama 58 detik (Gambar 5). Tundaan tersebut menyebabkan panjang antrian pada pintu Selatan sepanjang $70 \mathrm{~m}$ dengan jumlah kendaraan ringan sebanyak 5 kendaraan dan jumlah sepeda motor sebanyak 23 kendaraan (Gambar 6). Sedangkan panjang antrian pada pintu Utara ialah sepanjang $30 \mathrm{~m}$ dengan jumlah kendaraan ringan ringan sebanyak 3 kendaraan dan jumlah sepeda motor sebanyak 22 kendaraan (Gambar 6).

Dari hasil survai, juga diketahui bahwa pada akhir pekan, jumlah kendaraan yang tertunda di pintu Selatan cenderung lebih banyak dibandingkan jumlah kendaraan yang tertunda di pintu Utara. Hal ini dikarenakan di sisi utara terdapat Universitas Islam Negeri Sunan Kalijaga dan jalan raya yang mengarah ke jalan nasional Yogyakarta - Solo (arah kota). Sedangkan di sisi Selatan memang terdapat aktivitas perkantoran, sekolah, universitas dan pemukiman. Namun kemungkinan dikarenakan survai juga dilakukan pada akhir pecan maka aktivitas pergerakan transportasi masyarakat lebih banyak menuju ke arah Utara sehingga pelintas dari arah Utara ke Selatan lebih banyak jika dibandingkan perjalanan dari arah Selatan ke Utara. Selain itu, kendaraan yang tertunda didominasi oleh kendaraan ringan (KR) berupa mobil penumpang dan sepeda motor (SM).

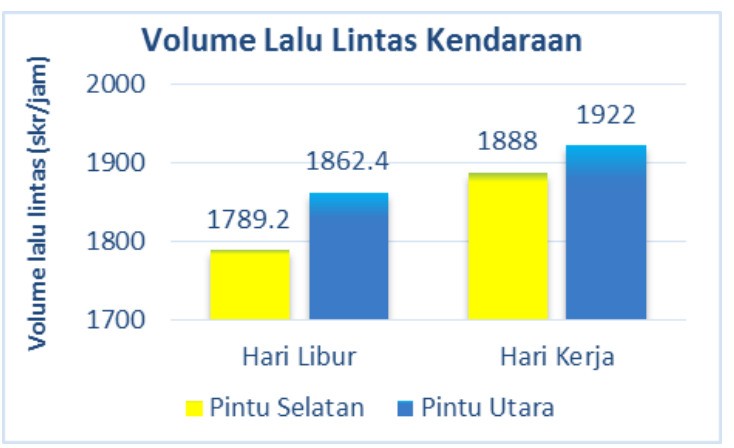

GAMBAR 4. Arus lalu lintas jalan raya (SKR/Jam)

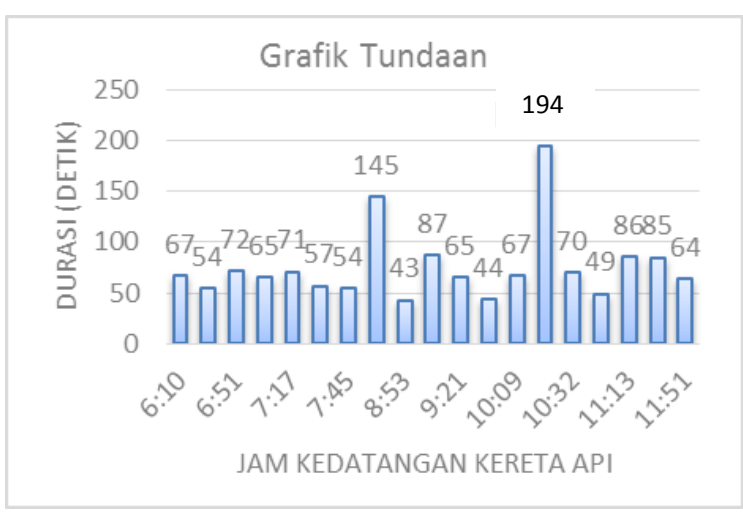

GAMBAR 5. Tundaan pada Hari Sabtu (akhir pekan) 


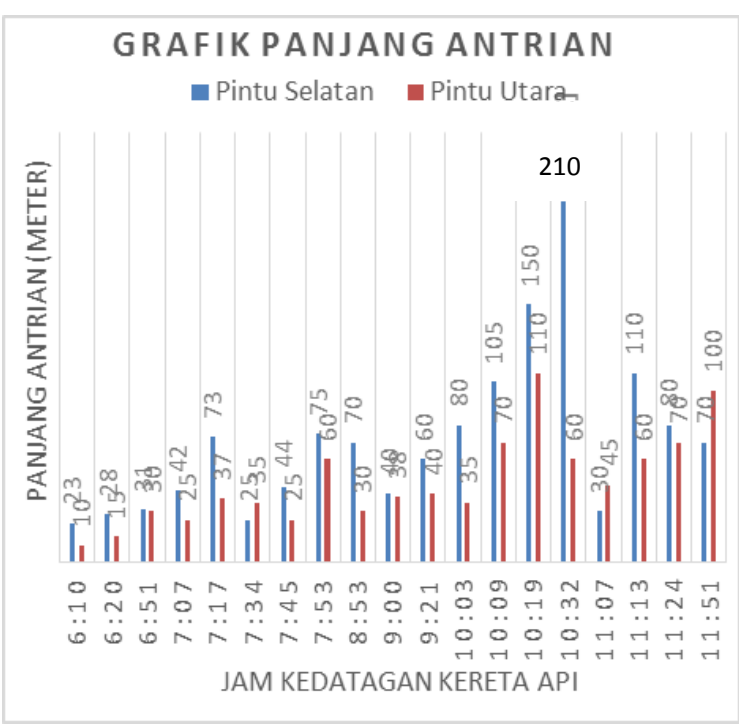

GAMBAR 6. Panjang antrian pada Hari Sabtu (akhir pekan)

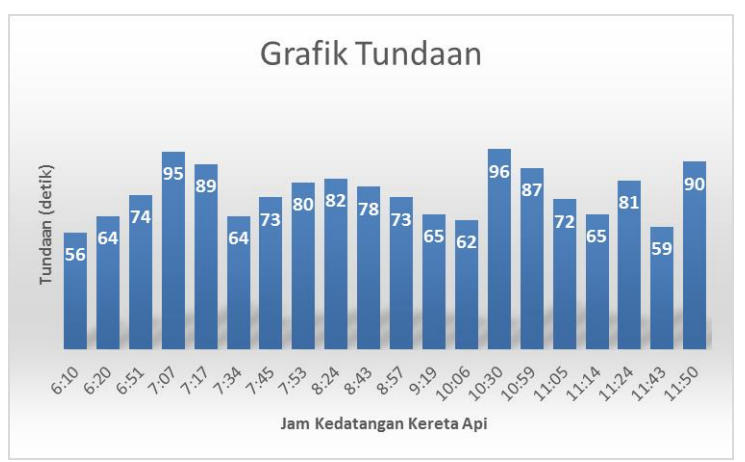

GAMBAR 7. Tundaan pada Hari Senin (hari kerja)

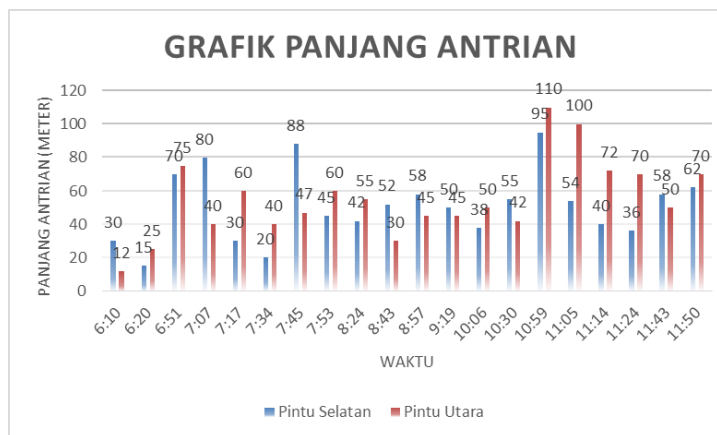

GAMBAR 8. Panjang antrian pada Hari Senin (hari kerja)

Berdasarkan hasil analisis survai pada hari Senin (mewakili hari kerja) yang tersaji pada Gambar 7, dapat disimpulkan bahwa tundaan terlama terjadi pada pukul 10:30 WIB dengan nilai tundaan selama 96 detik dan durasi proses pergerakan pintu perlintasan dimulai dari pintu perlintasan ditutup hingga pintu perlintasam dibuka membutuhkan waktu selama 108 detik. Tundaan tersebut menyebabkan panjang antrian pada pintu Selatan sepanjang $55 \mathrm{~m}$ dengan jumlah kendaraan ringan sebanyak 8 kendaraan dan jumlah sepeda motor sebanyak
55 kendaraan (Gambar 8). Sedangkan panjang antrian yang terjadi pada pintu Utara ialah sepanjang $42 \mathrm{~m}$ dengan jumlah kendaraan ringan sebanyak 5 kendaraan dan jumlah sepeda motor sebanyak 56 kendaraan (Gambar 8).

Selanjutnya tundaan tersingkat pada akhir pekan terjadi pada pukul 06:10 dengan tundaan selama 56 detik dan durasi proses pergerakan pintu perlintasan dimulai dari pintu perlintasan ditutup hingga pintu perlintasan dibuka membutuhkan waktu selama 70 detik (Gambar 7). Tundaan tersebut menyebabkan panjang antrian pada pintu Selatan sepanjang $30 \mathrm{~m}$ dengan jumlah kendaraan ringan sebanyak 5 kendaraan dan jumlah sepeda motor sebanyak 16 kendaraan (Gambar 8). Sedangkan panjang antrian pada pintu Utara ialah sepanjang $12 \mathrm{~m}$ dengan jumlah sepeda motor sebanyak 8 kendaraan (Gambar 8).

Dari hasil survai, juga diketahui bahwa pada hari kerja khususnya pagi hari, jumlah kendaraan yang tertunda di pintu Selatan cenderung lebih banyak dibandingkan jumlah kendaraan yang tertunda di pintu Utara. Sedangkan pada hari kerja khususnya siang hari, jumlah kendaraan yang tertunda di pintu Utara cenderung lebih banyak dibandingkan jumlah kendaraan yang tertunda di pintu Selatan. Hal ini dikarenakan di sisi utara terdapat Universitas Islam Negeri Sunan Kalijaga dan jalan raya yang mengarah ke jalan nasional Yogyakarta - Solo (arah kota). Sedangkan di sisi Selatan memang terdapat aktivitas perkantoran, sekolah, universitas dan pemukiman. Kemungkinan kondisi geografis ini yang menyebabkan aktivitas pergerakan transportasi masyarakat pada hari kerja di pagi hari lebih banyak menuju ke arah Utara dibandingkan ke Selatan, sedangkan pada siang hari aktivitas pergerakan transportasi masyarakat pada hari kerja lebih banyak menuju ke arah Selatan dibandingkan ke arah Utara. Selain itu, kendaraan yang tertunda didominasi oleh kendaraan ringan (KR) berupa mobil penumpang dan sepeda motor (SM).

\section{Analisis Kondisi Kerusakan Struktur Perkerasan Jalan}

Berdasarkan hasil analisis yang telah dilakukan, di dapat nilai rata-rata kondisi perkerasan jalan raya seperti disajikan pada Tabel 2. 
TABEL 2. Kualitas struktur perkerasan tiap unit segmen

\begin{tabular}{|c|c|c|c|}
\hline STA (km) & $\begin{array}{l}\text { CDV } \\
\text { maks }\end{array}$ & $\begin{array}{l}\text { PCI } \\
100- \\
\text { CDV }\end{array}$ & Keterangan \\
\hline $0+000 \mathrm{~s} / \mathrm{d} 0+025$ & 21 & 79 & Sangat Baik \\
\hline $0+025 \mathrm{~s} / \mathrm{d} 0+050$ & 62 & 38 & Buruk \\
\hline $0+050 \mathrm{~s} / \mathrm{d} 0+075$ & 49 & 51 & Sedang \\
\hline $0+075 \mathrm{~s} / \mathrm{d} 0+100$ & 0 & 100 & Sempurna \\
\hline $0+100 \mathrm{~s} / \mathrm{d} 0+125$ & 25 & 75 & Sangat Baik \\
\hline $0+125 \mathrm{~s} / \mathrm{d} 0+150$ & 0 & 100 & Sempurna \\
\hline $0+150 \mathrm{~s} / \mathrm{d} 0+175$ & 0 & 100 & Sempurna \\
\hline $0+175 \mathrm{~s} / \mathrm{d} 0+200$ & 57 & 43 & Sedang \\
\hline $0+200 \mathrm{~s} / \mathrm{d} 0+225$ & 59 & 41 & Sedang \\
\hline $0+225 \mathrm{~s} / \mathrm{d} 0+250$ & 34 & 66 & Baik \\
\hline $0+250 \mathrm{~s} / \mathrm{d} 0+275$ & 34 & 66 & Baik \\
\hline $0+275 \mathrm{~s} / \mathrm{d} 0+300$ & 0 & 100 & Sempurna \\
\hline $0+300 \mathrm{~s} / \mathrm{d} 0+325$ & 39 & 61 & Baik \\
\hline $0+325 \mathrm{~s} / \mathrm{d} 0+350$ & 8 & 92 & Sempurna \\
\hline $0+350 \mathrm{~s} / \mathrm{d} 0+375$ & 34 & 66 & Baik \\
\hline $0+375 \mathrm{~s} / \mathrm{d} 0+400$ & 12 & 88 & Sempurna \\
\hline \multirow{2}{*}{ Total } & & 1166 & \multirow{2}{*}{ Sangat Baik } \\
\hline & & 72,9 & \\
\hline
\end{tabular}

\section{KESIMPULAN}

Berdasarkan hasil inspeksi keselamatan yang sudah dilakukan pada perlintasan sebidang JPL 349 KM 163+758, Jalan Timoho, Kecamatan Gondokusuman, Kota Yogyakarta, dapat diambil kesimpulan bahwa perlintasan sebidang JPL 349 KM 163+758, Jalan Timoho, memiliki tingkat keselamatan yang cukup layak bagi pengendara kendaraan yang melintasi jalan raya dan perjalanan kereta api yang melintasi jalan kereta api pada perlintasan sebidang tersebut. Berdasarkan persyaratan kelengkapan infrastruktur dan geometrik pada perlintasan sebidang JPL 349 KM 163+758, Jalan Timoho, disimpulkan beberapa poin sebagai berikut: a) kelengkapan infrastruktur tidak memenuhi standar peraturan yang berlaku karena tidak adanya rambu larangan putar balik arah, tidak dijumpai marka jalan, selang waktu antar kereta api satu dengan kereta api berikutnya yang melintas kurang dari 7 menit, sudut perpotongannya antara jalan raya dan jalan kereta api $77^{\circ}$, serta jarak antar perlintasan sebidang kurang dari $800 \mathrm{~m}$, masing-masing $780 \mathrm{~m}$ (sisi Timur) 350 $\mathrm{m}$ (sisi Barat), b) geometrik pada jalan Timoho memiliki 2 tikungan yang berdekatan dengan perlintasan tersebut. Tikungan pertama memiliki jari-jari sebesar $24,26 \mathrm{~m}$ dengan kecepatan eksisting rata-rata $30 \mathrm{~km} / \mathrm{jam}$ yang tidak memenuhi persyaratan karena jari-jari eksisting lebih kecil dari jari-jari minimal 26 m. Sedangkan tikungan kedua memiliki jari- jari 41,17 m dengan kecepatan eksisting ratarata $35 \mathrm{~km} / \mathrm{jam}$ yang memenuhi persyaratan karena jari-jari eksisting lebih besar dari jarijari minimal 35,86 m. Selanjutnya panjang lurusan dihitung dari sisi terluar rel ke arah utara sebesar 35,04 m. Perancangan ulang alinyemen horizontal jalan raya menghasilkan sudut dan jari-jari tikungan yang lebih besar sehingga didapatkan jarak pandang pengendara saat akan melintasi perlintasan sebidang menjadi lebih baik dari sebelumnya.

Parameter-parameter yang dapat dianalisis akibat penutupan pintu perlintasan kereta api adalah: a) pada hari akhir pekan dan hari kerja, arus lalu lintas dari arah Utara ke Selatan lebih banyak dibandingkan dari arah Selatan ke Utara, b) durasi penutupan pintu perlintasan kereta api memberikan pengaruh yang signifikan terhadap besarnya tundaan dan panjang antrian kendaraan di jalan raya. Nilai indeks kondisi perkerasan (PCI) rata-rata pada Jalan Timoho adalah 72,9\% sehingga perkerasan jalan raya termasuk dalam kategori sangat baik (very good).

\section{DAFTAR PUSTAKA}

Direktorat Jenderal Perhubungan Darat. (2005). Pedoman Teknis Perlintasan Sebidang antara Jalan Raya dengan Jalan Kereta Api Nomor: SK.770/KA.401/DRJD/2005. Jakarta.

Hasan, B. (2009). Evaluasi Kelayakan Perlintasan Sebidang (Studi kasus: Perlintasan Sebidang Patukan, Gamping, Sleman, Yogyakarta). Tugas Akhir. Departemen Teknik Sipil dan Lingkungan Universitas Gajah Mada. Yogyakarta.

Kementerian Pekerjaan Umum. (2014). Pedoman Kapasitas Jalan Indonesia (PKJI). Jakarta.

Pramono, T. W. (2016). Analisis Kondisi Kerusakan Jalan pada Lapis Permukaan Perkerasan Lentur Menggunakan Metode Pavement Condition Index $(P C I)$. Tugas Akhir. Program Studi Teknik Sipil Universitas Muhammadiyah Yogyakarta. Yogyakarta.

Sekretariat Negara. (2007). Undang-undang Nomor 23 Tahun 2007 Tentang Perkeretaapian. Jakarta. 
Sekretariat Negara. (2009). Undang-undang Nomor 22 Tahun 2009 Tentang Lalu Lintas dan Angkutan Jalan. Jakarta.

Sekretariat Negara. (2011). Peraturan Menteri Perhubungan Nomor 36 Tahun 2011 Tentang Perpotongan dan Persinggungan antara Jalur Kereta Api dengan Bangun Lain. Jakarta.

Yulisetianto, D. H. (2008). Analisis Resiko pada Perlintasan Sebidang antara Jalan dan Jalur Kereta Api. Tugas Akhir. Departemen Teknik Sipil dan Lingkungan Universitas Gajah Mada. Yogyakarta.

PENULIS:

Noor Mahmudah

Program Studi Teknik Sipil, Fakultas Teknik, Universitas Muhammadiyah Yogyakarta, Kabupaten Bantul, D.I. Yogyakarta.

Email: noor.mahmudah@umy.ac.id

Dian M Setiawan

Program Studi Teknik Sipil, Fakultas Teknik, Universitas Muhammadiyah Yogyakarta, Kabupaten Bantul, D.I. Yogyakarta.

Email: diansetiawanm@ft.umy.ac.id

\section{Ristacya Devi Ramanti}

Program Studi Teknik Sipil, Fakultas Teknik, Universitas Muhammadiyah Yogyakarta, Kabupaten Bantul, D.I. Yogyakarta.

Email: acya_ristacya@ymail.com 